\title{
Validation of the DECA criteria for allergic conjunctivitis severity and control
}

\author{
M. Cesárea Sánchez-Hernández ${ }^{1 \dagger}$, Ana M. Navarro ${ }^{2,3^{*}+}$ —D, Carlos Colás ${ }^{4}$, Alfonso del Cuvillo ${ }^{5}$, Joaquín Sastre ${ }^{6,7,8}$, \\ Joaquim Mullol ${ }^{8,9 \dagger}$ and Antonio Valero $8,10+$
}

\begin{abstract}
Background: Allergic conjunctivitis (AC) is usually associated to allergic rhinitis (AR), but the severity and control of ocular symptoms should be assessed independently to improve diagnosis and treatment. The criteria from the Spanish consensus document on allergic conjunctivitis (DECA) aimed to be used as a patient-reported instrument for AC management. Here we validate these criteria for classifying AC severity and defining its control following COSMIN guidelines recommendations.
\end{abstract}

Methods: Patients with moderate or severe AR [reflective total nasal symptom score (rTNSS) score $\geq 8$ ] and concomitant AC were recruited from hospitals in Spain. Patients were classified according to the severity of ocular symptoms as mild, moderate, or severe, and classified with respect to control as controlled and non-controlled, using the DECA criteria. To validate these criteria, comparisons with the validated modified allergic rhinitis and its impact on asthma (mARIA), reflective total ocular symptom score (rTOSS), rhinitis control assessment test (RCAT), ESPRINT-15 questionnaires, a conjunctival hyperemia scale and a visual analogue scale (VAS) for ocular symptoms were performed.

Results: A total of 128 patients participated in the validation. Mean age was $34.4 \pm 12.1$ years; $72.7 \%$ were women. The DECA criteria showed a good discriminant validity, reflecting a high capacity to differentiate between mild, moderate, and severe patients, and controlled from uncontrolled patients. A strong association between AC and AR was reflected in the comparison between the DECA and the mARIA criteria $(p<0.0001)$. The DECA criteria for severity and control presented satisfactory properties for longitudinal validity and responsiveness.

Conclusions: Validation of the DECA criteria for severity and control of AC suggested that it can be useful in the evaluation of eye symptoms and follow-up of therapies.

Keywords: Allergic conjunctivitis, Allergic rhinoconjunctivitis, Conjunctivitis classification, Control, Ocular allergy

\section{Introduction}

Allergic conjunctivitis (AC) is an immunological hypersensitivity disorder of the ocular conjunctiva, predominantly mediated by an IgE mechanism [1]. AC occurs concomitantly with allergic rhinitis (AR) and other

\footnotetext{
*Correspondence: anam.navarro.sspa@juntadeandalucia.es

†M. Cesárea Sánchez-Hernández and Ana M. Navarro contributed equally as first authors

${ }^{\dagger}$ Joaquim Mullol and Antonio Valero contributed equally with senior responsibilities

${ }^{2}$ Department of Allergy, Hospital El Tomillar, Dos Hermanas, Seville, Spain

Full list of author information is available at the end of the article
}

allergic disorders in most patients, but the ocular symptoms can be present without nasal involvement in 2-7\% of $\mathrm{AC}$ patients [2,3]. AC is a highly prevalent disease, affecting up to $40 \%$ of the adult population [1]. The most frequent symptoms are pruritus, tearing, and conjunctival hyperemia. These symptoms can cause a significant impact on quality of life (QoL), affecting sleep and resulting in emotional problems and impairment of activities of daily living or social functions, such as work productivity or performance at school $[4,5]$. AC is often underdiagnosed and undertreated, as only a small proportion of patients $(\sim 10 \%)$ with AC symptoms seek medical advice 
[6]. Failure to recognize and treat ocular symptoms associated with AR can increase the burden of the disease substantially for allergy patients.

To better understand disease progression and to help assessing the effectiveness of treatment pathways, in the last two decades the concepts of 'disease severity' and 'disease control' have been established for chronic allergic diseases [7]. Thus, several patient-reported outcome (PRO) instruments have been developed to measure severity and control of AR [8,9]. A successful and widely discussed initiative was the allergic rhinitis and its impact on asthma (ARIA) approach, which classified patients according to severity and, more recently, also to control $[8,10,11]$. The original ARIA document classified AR severity based on the impact of AR on 4 items: sleep, activities/leisure/sports, work productivity/school performance and bothersome symptoms [8]. Based on the original ARIA criteria, a severity classification for AC patients based on ocular symptoms was also proposed [12].

In 2015, experts from the Spanish Societies of Allergology and Ophthalmology proposed a consensus of basic criteria that could be useful for both specialists and primary care physicians to facilitate the diagnosis, classification, control and treatment of patients with AC [13]. This consensus (henceforth named DECA, for its acronym in Spanish) was based on the modified ARIA (mARIA) classification of AR [14] adapted to AC (Fig. 1). The mARIA criteria classified patients as mild (when no items are affected), moderate (involvement of 1,2 or 3 items) and severe (involvement of the 4 items) in both untreated and treated patients [14, 15]. Accordingly, in the DECA classification three levels of severity were proposed (mild, moderate, severe) and the criteria for frequency were retained (intermittent/persistent).

The novel DECA criteria for control were based on the analysis of control criteria proposed for various allergic diseases [13]. AC was classified as controlled or uncontrolled based on 3 evaluation criteria: occurrence and frequency of ocular symptoms, a VAS score, and the degree of conjunctiva hyperemia as determined by the Efron scale [16].

The objective of this study was to validate the DECA criteria for classifying severity and control in $\mathrm{AC}$ patients, following the recommendations from the Consensusbased Standards for the Selection of Health Measurement Instruments (COSMIN) initiative [17], in a sample

a

\begin{tabular}{|c|c|c|c|}
\hline \multicolumn{2}{|c|}{$\begin{array}{c}\text { INTERMITTENT } \\
\leq 4 \text { days per week OR } \leq 4 \text { consecutive weeks }\end{array}$} & \multicolumn{2}{|c|}{$\begin{array}{c}\text { PERSISTENT } \\
>4 \text { days per week AND }>4 \text { consecutive weeks }\end{array}$} \\
\hline $\begin{array}{l}\text { MILD } \\
\text { - } \text { Signs and symptoms are } \\
\text { not bothersome } \\
\text { - No effect on vision } \\
\text { - No interference in school } \\
\text { or work tasks } \\
\text { - No difficulties for activities } \\
\text { of daily living, reading, } \\
\text { and/or sport }\end{array}$ & $\begin{array}{l}\text { MODERA } \\
\text { - Signs an } \\
\text { botherso } \\
\text { - Effect on } \\
\text { - Interfere } \\
\text { work tas } \\
\text { - Difficultie } \\
\text { daily livir } \\
\text { and/or sk }\end{array}$ & $\begin{array}{l}\text { (1-3 ítems) } \\
\text { ymptoms are } \\
\text { ion school or } \\
\text { activities of } \\
\text { eading, }\end{array}$ & $\begin{array}{l}\text { SEVERE (4 items) } \\
\text { - Signs and symptoms are } \\
\text { bothersome } \\
\text { - Effect on vision } \\
\text { - Interference in school or } \\
\text { work tasks } \\
\text { - Difficulties in activities of } \\
\text { daily living, reading, } \\
\text { and/or sport }\end{array}$ \\
\hline
\end{tabular}

\begin{tabular}{|c|c|c|}
\hline & $\begin{array}{l}\text { CONTROLLED } \\
\text { (all of the following) }\end{array}$ & $\begin{array}{l}\text { UNCONTROLLED } \\
\text { (at least } 1 \text { of the following) }\end{array}$ \\
\hline $\begin{array}{l}\text { Symptoms (pruritus, } \\
\text { tearing, visual discomfort) }\end{array}$ & $\begin{array}{l}\text { No symptoms or no } \\
\text { bothersome symptoms or } \\
\leq 2 \text { days/week }\end{array}$ & $\begin{array}{l}\text { Any intensity if present } \\
>2 \text { days/week }\end{array}$ \\
\hline Visual analog scale & $<5 \mathrm{~cm}$ & $\geq 5 \mathrm{~cm}$ \\
\hline Hyperemia (Efron scale) & $0-1$ & $2-4$ \\
\hline
\end{tabular}

Fig. 1 The criteria from the Spanish consensus document on allergic conjunctivitis (DECA). a Criteria for severity; b Criteria for control 
of AC patients included in an observational study on the control of allergic rhinitis in Spain (CORINA) study.

\section{Methods}

This study was part of a larger observational, prospective, and multicenter real-life study to assess the epidemiology of patients with moderate and severe AR in Spain in terms of control (CORINA), carried out between November 2015 and October 2016. Research was performed by allergists and/or otorhinolaryngologists working at reference hospitals and health centers throughout Spain. To avoid a possible bias due to seasonality, each researcher included no more than 4 consecutive patients meeting the inclusion criteria each month until reaching the target figure of 15 patients per investigator. The study was non-interventional as the clinical decision to prescribe treatments for the management of $\mathrm{AC}$ was made according to the usual clinical practice and was prior and independent of any consideration of the possible participation of patients in this study. During the study, patients received standard medical care without analytical tests or other clinical procedures specific to the study. All included patients had to sign informed consent and be able to attend the follow-up visit. The study was approved by the Ethics Committee for Clinical Research of the Hospital Clínic de Barcelona.

\section{Patient population and study design}

The inclusion criteria were age $\geq 18$ years and a diagnosis of AC according to the criteria in the DECA document [13] (Fig. 1). All patients had moderate or severe AR according to mARIA criteria [14], with a reflective total nasal symptom score (rTNSS) of $\geq 8$ (scale $0-12$ ).

The patients made a first visit (baseline visit) and a second visit 4-5 weeks later (follow-up visit). We followed COSMIN recommendations, as this international consensus established how to measure and evaluate in a uniform and consensual way the different health instruments [17]. According to COSMIN, the DECA severity and control criteria were validated for:

1. Discriminant validity was evaluated by comparing differences in the reflective total ocular symptom score (rTOSS), the rTNSS, question 3 of the rhinitis control assessment test (RCAT), a visual analogue scale (VAS), hyperemia scale and question 4 from the ESPRINT-15 questionnaire between patients classified in the different categories of severity or control using DECA criteria. Also, the percentage of patients classified in each category of severity using mARIA criteria was assessed for each category of AC severity by the DECA criteria.

2. Test-retest reliability was evaluated by analyzing the score agreement (kappa coefficient) in the basal and follow-up visits in those patients reporting equal $\mathrm{AC}$ severity or control. These patients were defined as those who had $<1.2$ changes in the VAS score or $\leq 1$ point in ESPRINT-15 question 4.

3. Responsiveness was assessed comparing the magnitude of the change in the different PROs (rTOSS, VAS, the Efron scale, and ESPRINT-15 question 4 for severity and rTOSS, ESPRINT-15 question 4, and RCAT question 3 for control) for three options of change in severity and control: worse, equal and improved.

\section{Patient-reported outcomes and assessments}

The values of all the study variables were extracted from the patients' medical records and from the study questionnaires filled out during the visits. Data was collected on demography, concomitant diseases and medication use, etiology of allergic sensitization, and severity and control of AC.

AC symptoms evaluated were pruritus, tearing and redness. Each of the symptoms was evaluated on a scale between 0 (no symptom) and 3 (severe symptom) and on a VAS $(0-10 \mathrm{~cm} ; 0=$ no symptoms, $10=$ maximum severity). Conjunctive hyperemia was measured with the grading scale by Efron $(0-4 ; 0=$ normal, $4=$ severe) [16]. The rTOSS was calculated as the sum to the individual score at 3 symptoms, with a maximum score of 9 . Question 3 of the Spanish-validated RCAT was used to evaluate control: "During the past week, how often did you have watery eyes?" $(5-1 ; 5=$ never, $1=$ extremely often) $[18,19]$. Question 4 of the Spanish version of the ESPRINT-15 questionnaire was used to evaluate affectation of quality of life: "In the past 2 weeks, how much have you been bothered by itchy eyes or having to rub your eyes?" $(0-6 ; 0=$ not at all; $6=$ extremely) $[20,21]$.

AC severity was classified according to the DECA criteria based on the impact on 4 items: bothersome symptoms, affectation of vision, interference with academic or work tasks, or interference with daily activities, reading and/or sport (Fig. 1a) [13]. Based on these criteria, patients were classified as mild (no items affected), moderate (involvement of 1, 2 or 3 items) and severe (involvement of the 4 items). AC was also classified according to its duration in intermittent (up to 4 days/week or up to 4 consecutive weeks) or persistent (more than 4 days/week and more than 4 consecutive weeks).

The degree of AC control was assessed, according to the DECA criteria, by symptoms, VAS and the Efron scale for conjunctival hyperemia (Fig. 1b) [13]. AC was considered controlled if there were no symptoms or they were not bothersome 2 or more days per week, VAS $<5 \mathrm{~cm}$ and hyperemia scale was $0-1$. It was considered uncontrolled if at least one of the following items was observed: symptoms with any intensity 2 or more days per week, VAS $\geq 5 \mathrm{~cm}$ and/or hyperemia scale was $2-4$. 


\section{Statistical methods}

For the statistical analysis, the package SAS version 9.2 for Windows was used. The mean, median, standard deviation, minimum and maximum, 25th and 75th percentiles, and the number of valid cases were used for the description of continuous variables. The number and percentage of patients per response category was used for categorical variables. Prior to performing parametric tests, we applied statistical techniques to ensure compliance with the assumptions. In case the established assumptions were not met, non-parametric tests were employed. A level of statistical significance (p-value) of $<0.05$ was used for all statistical tests.

\section{Results}

The CORINA study recruited 252 patients [18]. Of these, 198 (78.6\%) presented with AC symptoms in the basal visit, and 128 patients $(50.8 \%)$ in the followup visit. The validation of the DECA criteria for severity and control was performed on this sample of 128 patients with AC symptoms and who attended both the baseline and the follow-up visits. Table 1 shows the baseline characteristics of the patients included in this study. The mean age of the AC patients was $34.4 \pm 12.1$ years and $72.7 \%$ were women. The mean time elapsed between the date of diagnosis and the study was $6.3 \pm 9.7$ years. At the basal visit, $94.5 \%$ of patients presented pruritus, $85.9 \%$ tearing, and $85.9 \%$ redness. All patients presented moderate or severe AR (100\%) and $41.4 \%$ had concomitant asthma, 10.9\% atopic dermatitis, and $3.1 \%$ food allergy. The most frequent allergen sensitizations were to dust mites (57.7\%) and grass pollens $(45.5 \%)$, while $63 \%$ of the patients presented polysensitization. Regarding type of AC sensitization, for $25.2 \%$ of the patients it was seasonal, for $32.5 \%$ perennial, and for $42.3 \%$ both. Table 1 shows the treatment followed by the patients at baseline, which the specialist adjusted according to current guidelines at baseline, modifying it in $63.3 \%$ of cases and initiating it in $20.3 \%$.

\section{Validation of the DECA criteria for AC severity Discriminant validity}

Table 2 shows the scores of the different validated PROs when assessed according to the severity categories defined by using the DECA criteria. A highly significant discriminant validity of the DECA criteria for severity was found when comparing these scores. The percentage of patients classify similarly regarding severity with the MARIA criteria and the DECA criteria also showed a good balance facing both systems (Fig. 2).
Table 1 Baseline characteristics of the patients included in the DECA criteria for AC severity and control validation study $(\mathbf{N}=\mathbf{1 2 8})$

Age, years, mean (SD) $34.4(12.1)$

Gender, female, N (\%)

$93(72.7)$

Allergic comorbidities, N (\%)

AR

128 (100.0)

Asthma

53 (41.4)

Atopic dermatitis

14 (10.9)

Urticaria

Contact dermatitis

11 (8.6)

4 (3.1)

Food allergy

$4(3.1)$

Other

$14(10.9)$

Type of AC sensitization, N (\%)

Perennial

40 (32.5)

Seasonal

$31(25.2)$

Both

52 (42.3)

rTOSS score, mean (SD)

$5.4(2.3)$

Hyperemia (Efron scale), N (\%)

Normal

26 (20.3)

Trace

62 (48.4)

Mild

Moderate

29 (22.7)

$11(8.6)$

AC duration, N (\%)

Intermittent

$44(34.4)$

Persistent

84 (65.6)

Items reported (DECA), N (\%)

Bothersome symptoms

$116(90.6)$

Affecting vision

39 (30.5)

Interference with academic or work tasks

$54(42.2)$

Interference with daily activity, reading, sport

66 (51.6)

Severity (DECA criteria), N (\%)

Mild (no items affected)

$10(7.8)$

Moderate (1-3 items affected)

$93(72.7)$

Severe (4 items affected)

25 (19.5)

Control (DECA criteria), N (\%)

Controlled

27 (21.1)

Not controlled

$101(78.9)$

Ophthalmic treatments at baseline, N (\%)

Azelastine

34 (26.6)

Ketotifen

$11(8.6)$

Olopatadine

$3(2.3)$

Levocabastine

$1(0.8)$

Others

$1(0.8)$

Nasal treatments at baseline, N (\%)

Budesonide

2 (1.6)

Fluticasone

$12(9.4)$

Mometasone

$22(17.2)$

Triamcinolone

$1(0.8)$

Fluticasone furoate

43 (33.6)

Fluticasone/azelastine combination

$41(32.0)$

AC: allergic conjunctivitis; AR: allergic rhinitis; DECA: Spanish document on allergic conjunctivitis; rTOSS: reflective total ocular symptom score; SD: standard deviation 


\section{Test-retest reliability}

Thirty-three patients had the same AC severity as assessed by the VAS, resulting in a kappa value of 0.45 (72.7\% agreement) with the DECA severity criteria, and 56 patients for the ESPRINT-15 question 4, kappa value of 0.33 (62.5\% agreement), reflecting a fair test-retest reliability.

\section{Responsiveness}

The magnitudes of the change in the PROs scores for patients who worsened, improved or stayed the same in their AC severity were significantly different regarding rTOSS, VAS, the Efron hyperemia scale, and ESPRINT-15 question 4 (Fig. 3a), suggesting that the

Table 2 Mean (standard deviation) for the scores of the different validated patient reported outcomes assessed in the severity categories classified by using the DECA criteria

\begin{tabular}{|c|c|c|c|c|}
\hline & \multicolumn{3}{|c|}{ DECA criteria } & \multirow[t]{2}{*}{ p } \\
\hline & Mild & Moderate & Severe & \\
\hline \multicolumn{5}{|l|}{ Ocular symptoms (0-3), mean (SD) } \\
\hline Pruritus & $0.77(0.83)$ & $1.61(0.84)$ & $1.89(1.05)$ & $<0.0001$ \\
\hline Tearing & $0.47(0.78)$ & $1.25(0.89)$ & $1.78(1.09)$ & $<0.0001$ \\
\hline Redness & $0.43(0.68)$ & $1.28(1.01)$ & $1.78(0.83)$ & $<0.0001$ \\
\hline rTOSS score (0-9), mean (SD) & $1.66(1.98)$ & $4.17(2.28)$ & $5.44(2.65)$ & $<0.0001$ \\
\hline \multicolumn{5}{|c|}{ Ocular symptoms by VAS $(0-10 \mathrm{~cm})$, mean (SD) } \\
\hline Pruritus & $1.70(2.17)$ & $4.48(2.94)$ & $5.30(2.86)$ & $<0.0001$ \\
\hline Tearing & $1.45(2.30)$ & $3.80(2.95)$ & $4.79(3.20)$ & $<0.0001$ \\
\hline Redness & $1.35(2.41)$ & $3.94(3.05)$ & $4.56(3.03)$ & $<0.0001$ \\
\hline VAS global score & $1.82(2.21)$ & $4.87(2.88)$ & $6.14(3.01)$ & $<0.0001$ \\
\hline Efron hyperemia scale (0-4), mean (SD) & $0.10(0.31)$ & $0.93(0.81)$ & $1.20(1.14)$ & $<0.0001$ \\
\hline $\begin{array}{l}\text { ESPRINT-15 (0-6), mean (SD) } \\
\text { Question } 4^{*}\end{array}$ & $1.39(1.51)$ & $3.32(1.71)$ & $4.10(1.37)$ & $<0.0001$ \\
\hline
\end{tabular}

DECA: Spanish document on allergic conjunctivitis; ESPRINT-15: Spanish allergic rhinitis quality of life questionnaire; rTOSS: reflective total ocular symptom score; VAS: visual analogue scale; SD: standard deviation

*ESPRINT-15 Question 4:"In the past 2 weeks, how much have you been bothered by itchy eyes or having to rub your eyes?"

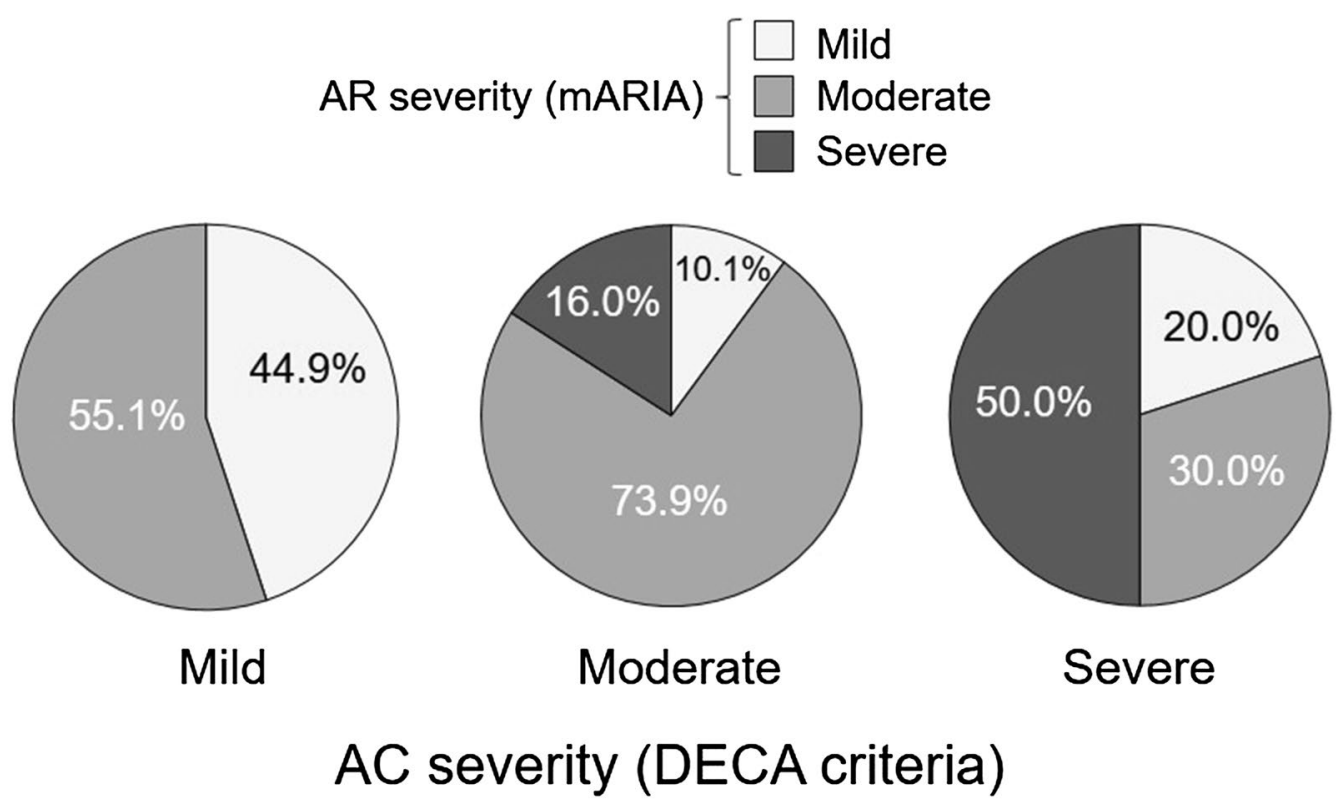

Fig. 2 Percentage of patients in each allergic conjunctivitis (AC) severity category using DECA criteria (mild, moderate, or severe) and for each allergic rhinitis (AR) severity category by mARIA 
DECA criteria for severity showed good responsiveness to detect changes on symptoms, ocular signs and quality of life.

\section{Validation of the DECA criteria for AC control}

Patients classified as controlled by the DECA criteria showed PROs scores significantly different from patients classified as uncontrolled, indicating a high discriminant validity of the DECA criteria for AC control (Table 3).

Patients who did not report changes in AC control, when assessed by DECA criteria, between the basal and follow-up visits $(\mathrm{N}=15)$ showed a similar score in PROs (Kappa value of $0.59 ; 80 \%$ agreement), proving a good test-retest validity.

The changes in PROs scores for patients who changed their level of control assessed by DECA criteria were significantly and relevantly higher than patients who do not, showing a good responsiveness (Fig. 3b).

\section{Discussion}

This study successfully validated the DECA criteria for severity and control of $\mathrm{AC}$ according to the requirements established in the COSMIN: discriminant validity, test-retest reliability, and responsiveness [17]. The data obtained in the CORINA study described here suggest that the DECA criteria could be used to rapidly assess AC severity and control of the disease in patients with $\mathrm{AC}$ symptoms.

Despite the increase in allergic eye diseases in recent decades and the socioeconomic impact generated by AC $[3-5,22]$, it is commonly accepted that $A C$ is often underdiagnosed and undertreated [6]. This could be due in part to the highly frequent comorbidity of $\mathrm{AC}$ with other more severe allergic diseases such as asthma [23]. In our study we also observed this frequent comorbidity, as asthma was present in $41.4 \%$ of the patients and atopic dermatitis in $10.9 \%$ (in addition to rhinitis which, for methodological reasons, was present in all patients). Another possible reason for the underdiagnosis of $\mathrm{AC}$ could be the lack of an unanimously agreed classification criteria. Additionally, in most epidemiological studies on allergic diseases the eye and nasal symptoms have been treated as a single clinical entity [24]. For these reasons, in an effort to bring together the classification criteria of $\mathrm{AC}$ and $\mathrm{AR}$ and to unify nomenclature on AC, the DECA consensus document proposed a new classification of $\mathrm{AC}$ and also added a proposal for the definition of AC control [13].

In this study some relevant properties of the DECA criteria were assessed. The discriminant validity for disease severity, as shown in Table 2, reflected a high capacity to differentiate mild, moderate, and severe patients. The extent by which AC is associated with AR could also be observed when patient classification by the DECA criteria were compared with the mARIA criteria. Although AR severity and AC severity do not necessarily have to follow parallel classifications, in our study we observe a good agreement between the two, suggesting that these instruments are effective and can simplify and expedite the classification of both diseases [25]. Additionally, we find it is highly useful to differentiate AC severity in three categories (mild, moderate, and severe), as differentiating moderate to severe patients can reduce the heterogeneity in the higher severity status $[14,15]$.

The capacity of the DECA criteria to discriminate patients according to the degree of AC control can be observed in Table 3 , clearly suggesting their validity. Longitudinal validity and responsiveness for the DECA criteria severity and control were also acceptable and suggest that they could be useful in the evaluation and follow-up of treated patients.

This validation study had some limitations. First, it only included patients with a diagnosis of moderate to severe AR or that patients with ocular symptoms alone were not included. Second, a methodological limitation derives from the lack of a standard and normalized classification for eye symptoms related to AC. For this reason, in our validation we could only compare the DECA criteria with other validated instruments previously applied to various aspects of symptom severity and quality of life formally designed for AR. We have also used the specific ocular items of the ESPRINT-15 and RCAT questionnaires (questions 4 and 3, respectively), but these items were not designed to be used in isolation and therefore their reliability has not been validated. Similarly, comparison with other classification schemes previously proposed before has not been possible, as they have not been validated.

One of the strengths of this study is that it showed for the first time the validation of an instrument specific for AC control, following the COSMIN recommendations for reliability, validity and responsiveness [17]. It has been suggested that measurements of disease control should be reproducible and easily implementable in everyday practice and focused on the disease's impact in daily life [9]. In this regard, the DECA criteria are designed to be a practical tool used by primary health practitioners and specialists alike. Further, the proposed clinical classification of AC severity is consistent and complementary with that currently in use for AR severity. The unification of criteria for the evaluation of severity and control is important in the development of diagnostic and treatment guidelines for common use by primary care physicians, allergists, and ophthalmologists, as a multidisciplinary communication is necessary for the optimal management of $\mathrm{AC}$ patients $[1,6,9]$. In this regard, the validated instruments described here could also be used to rapidly screen these patients with AC control 

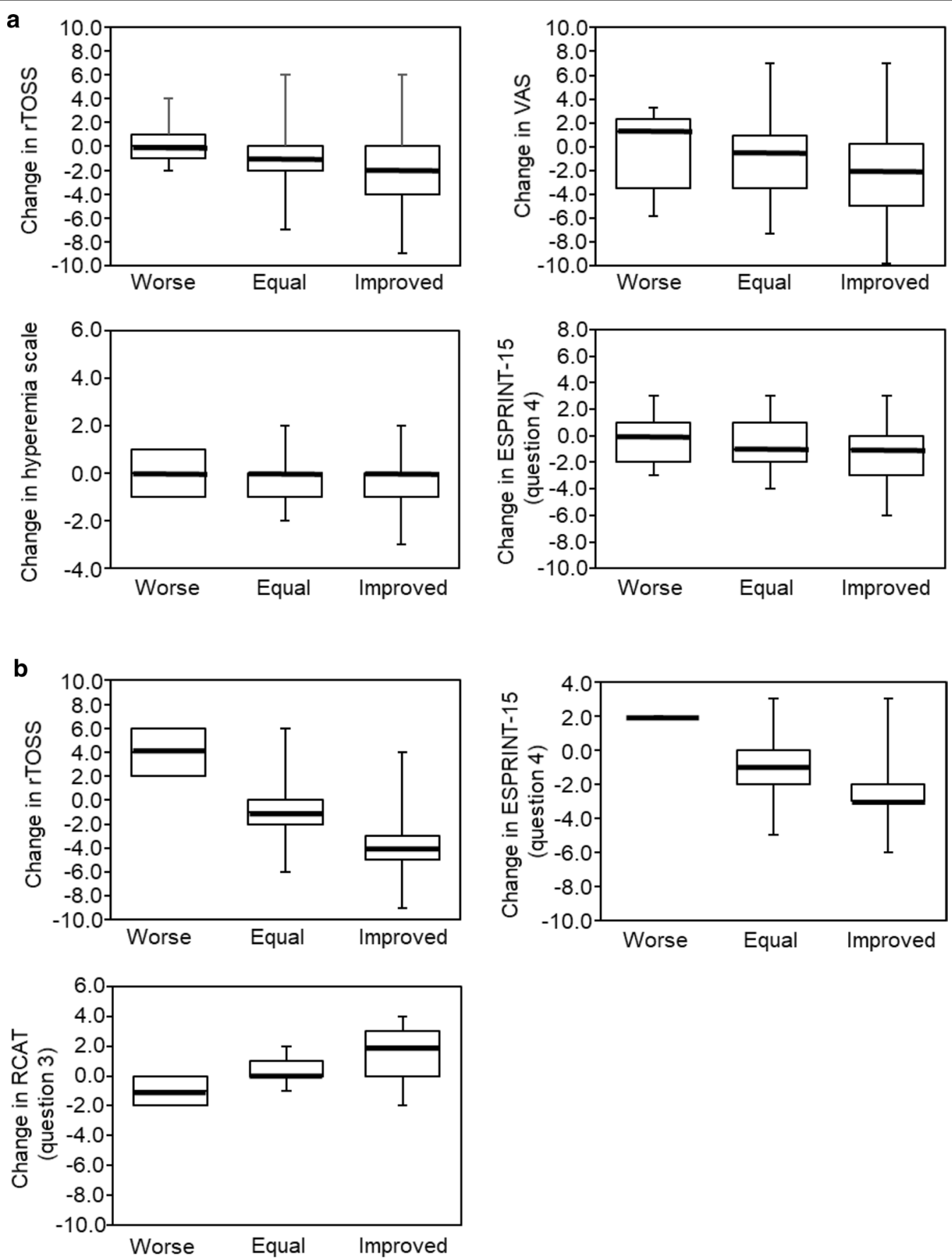

Fig. 3 Boxplots showing the DECA criteria score changes (median, 25th and 75th interquartile values) between visits for AC patients, which were categorized as worse, equal, or improved compared to baseline. a Comparisons for PROs evaluating severity. The differences are statistically significant for rTOSS ( $p<0.0001)$, VAS $(p<0.0001)$, hyperemia scale $(p<0.0002)$, and ESPRINT-15 question 4 ( $p<0.0001)$. $\mathbf{b}$ Comparisons for PROs evaluating control. The differences were statistically significant for rTOSS $(p<0.0001)$, ESPRINT-15 question $4(p<0.0001)$, and RCAT question 3 $(p<0.0002)$

problems and could help patients to communicate with health care practitioners about their disease and their response to treatment.

\section{Conclusion}

This study validated with good results the criteria for severity and control assessment proposed in DECA, making this a potentially useful tool for physicians and 


Table 3 Mean (standard deviation) of the different
validated patient reported outcomes for controlled
versus not controlled AC control assessed by the DECA
criteria

DECA criteria

p

\section{Controlled Not controlled}

Ocular symptoms (0-3), mean (SD)

$\begin{array}{llll}\text { Pruritus } & 0.94(0.86) & 2.00(0.71) & <0.0001 \\ \text { Tearing } & 0.65(0.89) & 1.62(0.82) & <0.0001 \\ \text { Redness } & 0.60(0.81) & 1.76(0.99) & <0.0001 \\ \text { rTOSS score (0-9), mean (SD) } & 2.19(2.25) & 5.38(1.97) & <0.0001 \\ \text { Ocular symptoms by VAS (0-10 cm), mean (SD) } & \\ \quad \text { Pruritus } & 0.94(0.86) & 2.00(0.71) & <0.0001 \\ \text { Tearing } & 0.65(0.89) & 1.62(0.82) & <0.0001 \\ \text { Redness } & 0.60(0.81) & 1.76(0.99) & <0.0001 \\ \text { ESPRINT-15 (0-6), mean (SD) } & 1.75(1.60) & 4.33(1.40) & <0.0001 \\ \text { Question 4* } & & & \\ \text { RCAT (5-1), mean (SD) } & 3.68(1.13) & 2.20(0.96) & <0.0001 \\ \text { Question 3** } & & & \end{array}$

DECA: Spanish document on allergic conjunctivitis; ESPRINT-15: Spanish allergic rhinitis quality of life questionnaire; RCAT: rhinitis control assessment test; rTOSS: reflective total ocular symptom score; VAS: visual analogue scale * ESPRINT-15 Question 4: "In the past 2 weeks, how much have you been bothered by itchy eyes or having to rub your eyes?"

** RCAT Question 3: "During the past week, how often did you have watery eyes?"

patients in the evaluation of eye symptoms and follow-up of therapies.

\begin{abstract}
Abbreviations
AC: Allergic conjunctivitis; AR: Allergic rhinitis; ARIA: Allergic rhinitis and its impact on asthma; COSMIN: Consensus-based standards for the selection of health measurement instruments; DECA: Consensus document on allergic conjunctivitis (Spanish acronym for "Documento de consenso sobre conjuntivitis alérgica"); ESPRINT-15: Spanish allergic rhinitis quality of life questionnaire; mARIA: Modified allergic rhinitis and its impact on asthma; PRO: Patientreported outcome; QoL: Quality of life; RCAT: Rhinitis control assessment test: rTNSS: Reflective total nasal symptom score; rTOSS: Reflective total ocular symptom score; VAS: Visual analogic scale.
\end{abstract}

\footnotetext{
Acknowledgements

The authors wish to thank Francisco López de Saro, PhD (Trialance SCCL) for medical writing assistance in the preparation of this article. The authors thank the participation in this study of María Teresa Dordal Culla (Hospital de Badalona, Barcelona); Encarnación Antón Casas (Hospital Marqués Valdecilla, Santander); Javier Montoro (Hospital Arnau de Vilanova, Valencia); Ignacio Jauregui Presa and Ignacio Antepara (Hospital de Basurto, Bilbao); Manuel Alcántara Villar (private practice, Jaén); Elisa Gómez Torrijos (Hospital Universitario Ciudad Real); Julio Delgado Romero (Hospital Virgen Macarena, Sevilla); Enric Figuerola Massana (Hospital Universitario Juan XXIII, Tarragona); Ramona Soler (Hospital Universitaroi Son Espases, Palma de Mallorca); Miguel Armengot Carceller (Hospital General Valencia); María Salas Cassinello (Hospital Carlos Haya, Málaga); Javier Fernández Arbeiza (Complejo Hospitalario, Cáceres); Alfonso Malet Casajuana (Private practice, Malet, Barcelona); Víctor Matheu Delgado (Hospital Quirón, Tenerife); Ruperto González (Clinic Alergocan, Tenerife); José Miguel Villacampa (Hospital de Collado-Villaba-IDC, Madrid); María Cesárea Sánchez (Hospital Juan Ramón Jiménez, Complejo Hospitalario de Huelva); Manuel de Barrio Fernández (Hospital Universitario Gregorio
}

Marañón, Madrid); Ignacio Dávila González (Hospital Clínico, Salamanca); Carmen Panizo Bravo (Hospital Nuestra Señora del Prado. Talavera de la Reina, Toledo); Víctor Soriano Gomis (Hospital General Alicante); María José Barasona Villarejo (Hospital Reina Sofía, Córdoba); José Luis Llorente Pendas and César Alvarez Marcos (Hospital Central Asturias, Oviedo); Jesús Bonnin Otal (Hospital General de Elda, Alicante); Dolores Hernández Fernández de Rojas (Hospital La Fe, Valencia); Francisco Vega de la Osada (Hospital Universitario La Princesa, Madrid); María Luisa González Gutiérrrez (Hospital Clínico San Carlos, Madrid); Pedro Amaro Merino (Instituto Oto Vértigo, Madrid); Albert Roger (Centre Roger Asmología y Alergia, Barcelona); Magdalena Lluch Bernal (Hospital Universitario de La Paz, Madrid); Beatriz Parra (Hospital El Bierzo. Ponferrada, León).

\section{Authors' contributions}

All authors contributed to study design, data acquisition and data analysis; MCS-H and AMN wrote the first draft of the manuscript; all authors participated in the writing and approved the final version of the manuscript before submission. All authors read and approved the final manuscript.

\section{Funding}

This study was funded by Meda Pharma SL (a Mylan company).

\section{Availability of data and materials}

Data is available from the corresponding author upon reasonable request.

\section{Ethics approval and consent to participate}

The study was approved by the Ethics Committee for Clinical Research of the Hospital Clínic de Barcelona. All patients signed informed consent to participate.

\section{Consent for publication}

All participants signed their written consent for publication.

\section{Competing interests}

MCS-H reports grants from MYLAN during the conduct of the study. Outside this study, she reports personal fees from MYLAN, Sanofi, Novartis, and Merck. AMN reports grants from MYLAN during the conduct of the study. Outside this study, she reports personal fees from GSK, AstraZeneca, Merck, and MYLAN. CC reports having served as a consultant to Mylan and AstraZeneca; having been paid lecture fees by AstraZeneca, GSK, Mylan, and MSD; and grants from Roxall, Novartis, AstraZeneca, and Sanofi. AdC reports grants from MYLAN during the conduct of the study. Outside this study, he reports grants and personal fees from MYLAN, FAES Pharma, Novartis, Allakos, and Sanofi; and personal fees from ALK, GSK, and MSD. JS reports grants from MEDA during the conduct of the study; grants and personal fees from SANOFI; and personal fees from GSK, NOVARTIS, ASTRA ZENECA, MUNDIPHARMA, and FAES FARMA, outside the submitted work. JM reports personal fees and other from SANOFIGENZYME \& REGENERON, NOVARTIS; grants and personal fees from MYLANMEDA Pharma and URIACH Group; and personal fees from Mitsubishi-Tanabe, Menarini, UCB, AstraZeneca, GSK, and MSD, outside the submitted work. AV reports grants from MEDA during the conduct of the study.

\section{Author details}

${ }^{1}$ Department of Allergy, Hospital Universitario Virgen Macarena, Seville, Spain.

${ }^{2}$ Department of Allergy, Hospital El Tomillar, Dos Hermanas, Seville, Spain.

${ }^{3}$ Doctor Relimpio 6, 3B, 41003 Seville, Spain. ${ }^{4}$ Department of Allergy, Hospital Clínico-Instituto de Investigación Sanitaria de Aragón, Zaragoza, Spain.

${ }^{5}$ Rhinology \& Asthma Unit; Department of Otorhinolaryngology, Hospital Universitario de Jerez, Cádiz, Spain. ${ }^{6}$ Department of Allergy, Fundación Jiménez Díaz, Madrid, Spain. ${ }^{7}$ Department of Medicine, Universidad Autónoma de Madrid, Madrid, Spain. ${ }^{8}$ CIBERES, Instituto de Salud Carlos III, Madrid, Spain.

${ }^{9}$ Rhinology Unit \& Smell Clinic, Department of Otorhinolaryngology, Hospital Clinic, Institut d'Investigacions Biomèdiques August Pi i Sunyer (IDIBAPS), Universitat de Barcelona, Barcelona, Spain. ${ }^{10}$ Department of Pneumology and Allergy, Hospital Clínic, Institut d'Investigacions Biomèdiques August Pi i Sunyer (IDIBAPS), Barcelona, Spain.

Received: 30 July 2020 Accepted: 8 October 2020

Published online: 23 October 2020 


\section{References}

1. Dupuis P, Prokopich $\mathrm{CL}$, Hynes A, Kim H. A contemporary look at allergic conjunctivitis. Allergy Asthma Clin Immunol. 2020;16:5.

2. Ojeda P, Sastre J, Olaguibel JM, Chivato T. Alergologica 2015: a National Survey on Allergic Diseases in the Adult Spanish Population. J Investig Allergol Clin Immunol. 2018;28:151-64.

3. Singh K, Axelrod S, Bielory L. The epidemiology of ocular and nasal allergy in the United States, 1988-1994. J Allergy Clin Immunol. 2010;126(778-83):e6.

4. Smith AF, Pitt AD, Rodruiguez AE, Alio JL, Marti N, Teus M, et al. The economic and quality of life impact of seasonal allergic conjunctivitis in a Spanish setting. Ophthalmic Epidemiol. 2005;12:233-42.

5. Pitt AD, Smith AF, Lindsell L, Voon LW, Rose PW, Bron AJ. Economic and quality-of-life impact of seasonal allergic conjunctivitis in Oxfordshire. Ophthalmic Epidemiol. 2004;11:17-33.

6. Bielory L, Delgado L, Katelaris $\mathrm{CH}$, Leonardi A, Rosario N, Vichyanoud P. ICON: diagnosis and management of allergic conjunctivitis. Ann Allergy Asthma Immunol. 2020:124:118-34.

7. Hellings PW, Fokkens WJ, Akdis C, Bachert C, Cingi C, Dietz de Loos D, et al. Uncontrolled allergic rhinitis and chronic rhinosinusitis: where do we stand today? Allergy. 2013;68:1-7.

8. Bousquet J, Van Cauwenberge P, Khaltaev N. Allergic rhinitis and its impact on asthma. J Allergy Clin Immunol. 2001;108:S147-334.

9. Demoly P, Calderon MA, Casale T, Scadding G, Annesi-Maesano I, Braun JJ, et al. Assessment of disease control in allergic rhinitis. Clin Transl Allergy. 2013;3:7.

10. Bousquet J, Arnavielhe S, Bedbrook A, Fonseca J, Morais Almeida M, Todo Bom A, et al. The allergic rhinitis and its impact on asthma (ARIA) score of allergic rhinitis using mobile technology correlates with quality of life: the MASK study. Allergy. 2018;73:505-10.

11. Brozek JL, Bousquet J, Agache I, Agarwal A, Bachert C, Bosnic-Anticevich $\mathrm{S}$, et al. Allergic rhinitis and its impact on Asthma (ARIA) guidelines-2016 revision. J Allergy Clin Immunol. 2017;140:950-8.

12. Leonardi A, Bogacka E, Fauquert JL, Kowalski ML, Groblewska A, Jedrzejczak-Czechowicz M, et al. Ocular allergy: recognizing and diagnosing hypersensitivity disorders of the ocular surface. Allergy. 2012;67:1327-37.

13. Sánchez-Hernández MC, Montero J, Rondón C, Benitez del Castillo JM, Velázquez E, Herreras JM, et al. Consensus document on allergic conjunctivitis (DECA). J Investig Allergol Clin Immunol. 2015;25:94-106.

14. Valero A, Ferrer M, Sastre J, Navarro AM, Monclus L, Marti-Guadano E, et al. A new criterion by which to discriminate between patients with moderate allergic rhinitis and patients with severe allergic rhinitis based on the allergic rhinitis and its impact on asthma severity items. J Allergy Clin Immunol. 2007:120:359-65.
15. Valero A, Ferrer M, Baro E, Sastre J, Navarro AM, Marti-Guadano E, et al. Discrimination between moderate and severe disease may be used in patients with either treated or untreated allergic rhinitis. Allergy. 2010;65:1609-13

16. Efron N, Morgan PB, Katsara SS. Validation of grading scales for contact lens complications. Ophthalmic Physiol Opt. 2001;21:17-29.

17. Mokkink LB, Terwee CB, Patrick DL, Alonso J, Stratford PW, Knol DL, et al. The COSMIN study reached international consensus on taxonomy, terminology, and definitions of measurement properties for health-related patient-reported outcomes. J Clin Epidemiol. 2010;63:737-45.

18. Del Cuvillo A, Sastre J, Colas C, Navarro AM, Mullol J, Valero A. Adaptation to Spanish and validation of the Rhinitis Control Assessment Test (RCAT) questionnaire. J Investig Allergol Clin Immunol. 2020;30:175-81.

19. Nathan RA, Dalal AA, Stanford RH, Meltzer EO, Schatz M, Derebery J, et al. Qualitative development of the rhinitis control assessment test (RCAT), an instrument for evaluating rhinitis symptom control. Patient. 2010;3:91-9.

20. Valero A, Alonso J, Antepara I, Baro E, Colas C, del Cuvillo A, et al. Development and validation of a new Spanish instrument to measure health-related quality of life in patients with allergic rhinitis: the ESPRINT questionnaire. Value Health. 2007;10:466-77.

21. Valero A, Izquierdo I, Sastre J, Navarro AM, Baro E, Marti-Guadano E, et al. ESPRINT-15 questionnaire (Spanish version): reference values according to disease severity using both the original and the modified ARIA classifications. J Investig Allergol Clin Immunol. 2013;23:14-9.

22. Rosario N, Bielory L. Epidemiology of allergic conjunctivitis. Curr Opin Allergy Clin Immunol. 2011;11:471-6.

23. Neto HJ, Rosario NA, Westphal GL, Riedi CA, Santos HL. Allergic conjunc tivitis in asthmatic children: as common as underreported. Ann Allergy Asthma Immunol. 2010;105:399-400.

24. Sánchez M, Fernández Parra B, Matheu V, Navarro A, Ibáñez M, Dávila I, et al. Allergic conjunctivitis. J Allergy Clin Immunol. 2011;21:1-19.

25. Gradman J, Wolthers OD. Allergic conjunctivitis in children with asthma, rhinitis and eczema in a secondary outpatient clinic. Pediatr Allergy Immunol. 2006;17:524-6.

\section{Publisher's Note}

Springer Nature remains neutral with regard to jurisdictional claims in published maps and institutional affiliations.
Ready to submit your research? Choose BMC and benefit from:

- fast, convenient online submission

- thorough peer review by experienced researchers in your field

- rapid publication on acceptance

- support for research data, including large and complex data types

- gold Open Access which fosters wider collaboration and increased citations

- maximum visibility for your research: over 100M website views per year

At $B M C$, research is always in progress.

Learn more biomedcentral.com/submissions 